\title{
Ice motion over Lake Vostok, Antarctica: constraints on inferences regarding the accreted ice
}

\author{
R. Kwok, ${ }^{1}$ M. J. Siegert, ${ }^{2}$ F. D. Carsey ${ }^{1}$ \\ ${ }^{1}$ Jet Propulsion Laboratory, California Institute of Technology, 4800 Oak Grove Drive, Pasadena, California 91109, U.S.A. \\ ${ }^{2}$ Bristol Glaciology Centre, School of Geographical Sciences, University of Bristol, Bristol BS8 1SS, England
}

\begin{abstract}
Ice motion over Lake Vostok, Antarctica, is measured using repeat-pass synthetic-aperture radar (SAR) interferometry. The coverage of the lake and the components of the vector field are resolved using 10 overlapping data takes from ascending and descending look directions. Seventy-day temporal baselines provide the sensitivity required to observe the range of ice motion $\left(0-6 \mathrm{~m} \mathrm{a}^{-1}\right)$ over the lake and the adjacent ice sheet. It is remarkable that the scattering field remained coherent over these time separations. This is critical for interferometric analysis and can be attributed to the low surface accumulation and low air temperature at this elevation. The regional flow of the ice sheet around Lake Vostok is from west to east, perpendicular to the surface elevation contours. As the ice flows past the grounding line, a southward component of motion develops that is correlated with the north-south surface slope along the length of the lake. The surface velocity increases slowly from the northern tip of the lake and then more rapidly south of $77^{\circ} \mathrm{S}$. At Vostok station, the ice motion is $4.2 \mathrm{~m} \mathrm{a}^{-1}$. Across the lake and away from boundary effects, the down-lake flow pattern takes on a parabolic profile with maximum velocity close to the center line of the lake. The overall influence of the subglacial lake is the addition of a down-lake motion component to the prevailing west-east motion of the ice sheet. As a result, we estimate $10 \%$ of the mass flowing onto the lake is diverted south. Reconstructions based on the Vostok ice core indicate that the ice was grounded up-glacier from the core site approximately 5000 years ago. This suggests a minimum freezing rate of $40 \mathrm{~mm} \mathrm{a}^{-1}$ for the subglacial accretion ice, 10 times greater than that inferred from thermodynamic modeling of the upper $2 \mathrm{~km}$ of the ice core.
\end{abstract}

\section{INTRODUGTION}

Although Antarctic subglacial lakes were discovered over 20 years ago (e.g. Robin and others, 1977), the effect they have on overlying ice-sheet dynamics has yet to be quantified. The largest subglacial lake is located beneath Vostok station, central East Antarctica (Kapitsa and others, 1996; Siegert and Ridley, 1998). The European Remote-sensing Satellite (ERS-1) altimeter indicates that the ice-sheet surface above Lake Vostok is unusually smooth and flat. This morphology is caused by changes in the dynamics of ice, which floats over the subglacial lake. Since shear stress across the ice--water boundary above subglacial lakes is effectively zero, the ice sheet must flow over the lake by a mechanism (probably longitudinal extension) similar to that in ice shelves, rather than by the base-parallel shear deformation that occurs in cold-based grounded ice. Consequently, the dynamic characteristics of the ice sheet will be altered as ice flows across the margin of the lake, as the basal shear stress is reduced to zero. The aim of this paper is to measure the ice-velocity field over Lake Vostok from interferometric synthetic-aperture radar (InSAR) data. The effects of the subglacial lake on the large-scale motion field on ice-sheet mass balance, bottom ablation/accretion and the origins of the Vostok ice core are briefly discussed.

\section{Glaciological setting}

The areal extent of the Vostok subglacial lake can be esti- mated from two geophysical datasets: (1) airborne radar which supplies information from the ice-sheet base, and (2) satellite altimetry (from the ERS-1 satellite) of the flat region on the ice-sheet surface above the subglacial lake (Siegert and Ridley, 1998).

There is a very strong correlation between the airborne radar-determined location of Lake Vostok (Robin and others, 1977; Ridley and others, 1993; Kapitsa and others, 1996) and the position of the anomalous flat-surfaced region of the ice sheet above the lake (Siegert and Ridley, 1998). The margin of the flat surface region matches so well with the radar-observed edge of the lake that the lake extent can be mapped accurately from the satellite altimetry (Kapitsa and others, 1996).

Lake Vostok is $230 \mathrm{~km}$ long and up to $50 \mathrm{~km}$ wide, with a surface area of $\sim 14000 \mathrm{~km}^{2}$, making it one of the world's largest lakes. Figure 1 shows synthetic-aperture radar (SAR) images of surface of the overlying ice cover. Satellite-radar altimetry indicates that the ice sheet above Lake Vostok has an approximately north-south surface slope of $0.004^{\circ}$ $\left(0.25 \mathrm{~m} \mathrm{~km}^{-1}\right)$. The ice-sheet surface thus drops by about $40 \mathrm{~m}$ across the $230 \mathrm{~km}$ length of the lake. The relatively flat ice-sheet surface over Lake Vostok contrasts with the surface slope of the surrounding ice sheet. Both to the east and west of the lake, the surface slope of the grounded ice sheet is relatively uniform at approximately $0.08^{\circ}\left(1.4 \mathrm{~m} \mathrm{~km}^{-1}\right)$. The general direction of grounded ice flow, assumed to be parallel to the surface slope, alters from northeastward around the 

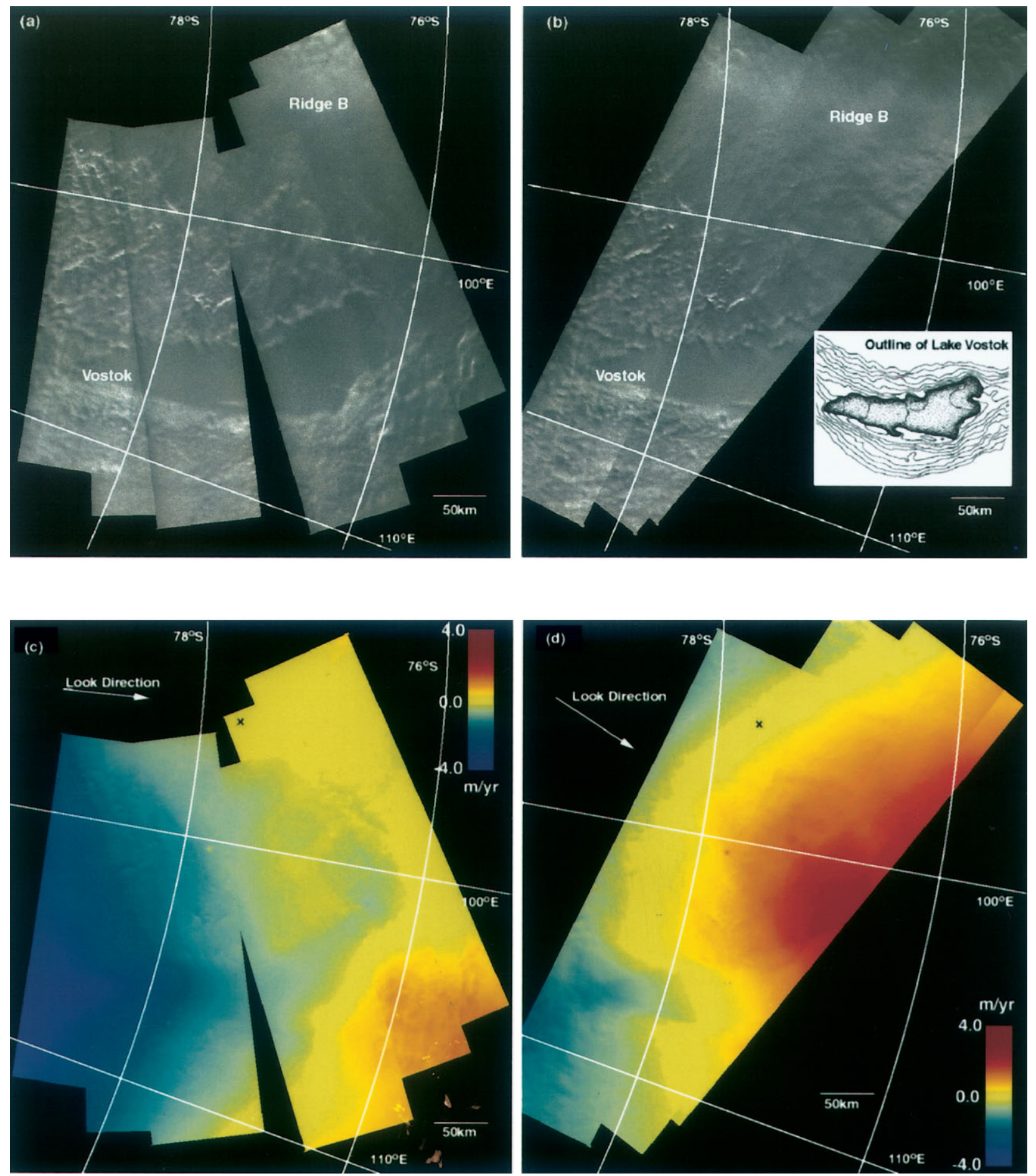

Fig. 1. ERS-1 SAR image mosaics and one-dimensional motion fields of the ice overlying LakeVostok. (a) Ascending data takes. (b) Descending data takes (inset shows the outline of LakeVostok). (c) Component of motion derived from the ascending interferometric data takes. (d) Component of motion derived from the descending data takes. Radar line-of-sight directions (look direction arrow) are projected onto the plane tangent to the local ellipsoid. The motion is referenced to a stationary point (indicated by a cross) on the ridge B ice divide. The image maps are presented on a polar stereographic projection centered at the South Pole, with the map vertical defined by the Greenwich meridian. The dimensions of the images are $463 \mathrm{~km}$ by $505 \mathrm{~km}$. (ERS-1 images (C) European Space Agency 1999)

northern end of Lake Vostok to eastward near to the south of the lake (Siegert and Ridley, 1998). A few kilometres east of, and along the $200 \mathrm{~km}$ long western margin of, the lake lies a small $(\sim 2 \mathrm{~m})$ trough in the ice-sheet surface, about $10 \mathrm{~km}$ wide. Also, a few kilometres east of the eastern margin of the lake, a small topographic rise occurs. It is approximately $5 \mathrm{~m}$ high, $10 \mathrm{~km}$ wide and $>200 \mathrm{~km}$ long.

Through analysis of the airborne radar data, the ice thickness over Lake Vostok and the subglacial topography have been measured (Siegert and Ridley, 1998). Ice thickness is $>4200 \mathrm{~m}$ over the northern region of the lake, and thins steadily along the length of the lake such that beneath Vostok station at the southern end of the lake it is $3740 \mathrm{~m}$. The height of the lake surface at its northern end is around $-700 \mathrm{~m}$ a.s.l. This elevation increases toward the south of the lake where, beneath Vostok station, the surface elevation of the lake is around $-300 \mathrm{~m}$. The north-south subglacial gradient at the ice-lake interface is around 10 times greater than, and in the opposite direction to, the surface slope of the ice sheet.

Lake Vostok is located within a subglacial topographic 
basin, the topographic setting of which is characteristic of a rift valley. The basin has a crescentic shape, and the side walls are relatively steep (with gradients up to 0.1) and high (up to $1000 \mathrm{~m}$ above the surface of the lake). When one considers that Lake Vostok is $500 \mathrm{~m}$ deep in the south and may have several hundred metres of glacial sediments over its floor (Kapitsa and others, 1996), the subglacial valley may be as much as $2000 \mathrm{~m}$ deep and $5000 \mathrm{~m}$ below the surface of the ice sheet.

\section{THE ICE-MOTION FIELD}

\section{ERS tandem mission dataset}

The ERS-1 SAR data used here were acquired during the ERS tandem mission. The data from the ERS-1/-2 radars acquired over the region around Lake Vostok were captured at the McMurdo Reception Facility and shipped to the Alaska SAR Facility (ASF) for archive and distribution. The 10 SAR data takes, containing 42 frames of SAR data, were provided by ASF. The details of the dataset are shown in Table 1. The SAR image mosaics of the ascending and descending data takes used in the motion analysis are shown in Figure 1.

\section{Repeat-pass interferometry}

We construct the flow field with motion observations from repeat-pass interferometry acquired during the ascending and descending data takes. For background discussions on the theory and techniques for derivation of glacial motion and topography using repeat-pass interferometry, the reader is referred to the published literature (Goldstein and others, 1993; Kwok and Fahnestock, 1996; Joughin and others, 1998). Briefly, the interferometric phase of a given sample can be expressed as the sum of topography- and displacementdependent terms

$$
\phi=\phi_{\text {topography }}+\phi_{\text {displacement }} .
$$

The first term, $\phi_{\text {topography }}$, contains phase variations from surface relief, the sensitivity of which is directly proportional to the length of the interferometric baseline. If the surface is displaced along the radar line-of-sight between repeat observations, then the observed phase includes a second phase contribution, $\phi_{\text {displacement, }}$ where

$$
\phi_{\text {displacement }}=\frac{4 \pi}{\lambda} v_{\mathrm{s}} \Delta T \sin \theta .
$$

$\lambda$ is the radar wavelength, $v_{\mathrm{s}} \Delta T$ is the radar line-of-sight motion, $\theta$ is the incidence angle, and $\Delta T$ is the time separation between observations. $v_{\mathrm{s}}$ represents the component of surface velocity in the radar look direction. This term is independent of the spatial baseline and is dependent on only the temporal baseline, $\Delta T$. Available temporal baselines from the ERS tandem mission are 1, 35 and $70 \mathrm{~d}$. For these baselines, a $2 \pi \mathrm{rad}$ (1 fringe) change in $\phi_{\text {displacement }}$ is equivalent to a change in velocity $(v)$ of $26.1,0.75$ and $0.37 \mathrm{~m} \mathrm{a}^{-1}$, respectively. Based on the magnitude of the velocities (0-6 $\mathrm{m} \mathrm{a}^{-1}$ ) around Lake Vostok, the $70 \mathrm{~d}$ temporal baseline provides the maximum sensitivity to small variations in the motion field, and this is what we use in the following analyses.

\section{Target coherence}

Typically, the use of long temporal baselines to detect surface motion is limited by the coherence of the target scattering field over the time separation. If scattering properties are altered by precipitation or other physical processes, then the coherence is reduced or destroyed. Table 1 shows the coherence of $25 \mathrm{~km}$ by $25 \mathrm{~km}$ sample regions on the lake surface for all the interferometric pairs used in our analysis. We note that the repeat-pass interferograms used here have the longest temporal baselines ever attempted for detection of ice motion. Modest coherence is maintained for all the data-take pairs. We attribute this to the below-freezing temperatures and low accumulation rate $\left(\sim 30 \mathrm{~mm} \mathrm{a}^{-1}\right)$ at this elevation on the ice sheet. A dependence of the coherence on the perpendicular baseline length, $B_{\perp}$, is evident. The highest coherence is exhibited by the samples from the data-take pair with the shortest baseline, and the lowest coherence by the samples from the pair with the longest baseline. $B_{\perp}$ is the component of the baseline perpendicular to the radar look direction and is a measure of the angular separation between the observation points. Decorrelation due to perpendicular baseline separation well below the critical baseline $(\sim 1 \mathrm{~km}$ for ERS) is believed to be dependent on the vertical extent of the scattering medium. Indeed, for volume-scattering media like snow and glacial ice, this dependence has been used to estimate the penetration depth of the radio waves into the scattering volume (Hoen and Zebker, 1999).

\section{Estimation of the two-dimensional motion fields}

The one-dimensional motion estimates from individual ascending and descending data takes are produced by first removing the topographic contribution, $\phi_{\text {topography, to the }}$

\begin{tabular}{|c|c|c|c|c|c|c|c|}
\hline Data take & Date & Data take & Date & $A s c / D s c$ & $B_{\perp}$ & $B_{\|}$ & Correlation (on lake) \\
\hline 23993 & 15 Feb. 1996 & 24995 & 25 Apr. 1996 & A & 61.97 & -59.75 & $0.41 \pm 0.09$ \\
\hline 23793 & 1 Feb. 1996 & 24795 & 11 Apr. 1996 & $\mathrm{~A}$ & -61.32 & -95.82 & $0.42 \pm 0.09$ \\
\hline 23965 & 13 Feb. 1996 & 24967 & 23 Apr. 1996 & A & 96.10 & -38.93 & $0.31 \pm 0.12$ \\
\hline 23765 & 30 Feb. 1996 & 24767 & 9 Apr. 1996 & A & -104.40 & -112.36 & $0.32 \pm 0.09$ \\
\hline 23894 & 8 Feb. 1996 & 24896 & 18 Apr. 1996 & $\mathrm{~A}$ & 240.72 & 16.53 & $0.23 \pm 0.09$ \\
\hline 23935 & 11 Feb. 1996 & 24937 & 21 Apr. 1996 & $\mathrm{D}$ & 129.25 & -26.24 & $0.35 \pm 0.09$ \\
\hline 23949 & 12 Feb. 1996 & 24951 & 22 Apr. 1996 & $\mathrm{D}$ & 83.36 & -44.85 & - \\
\hline 23820 & 3 Feb. 1996 & 24822 & 13 Apr. 1996 & $\mathrm{D}$ & 15.90 & -68.09 & $0.50 \pm 0.08$ \\
\hline 23777 & 31 Feb. 1996 & 24779 & 10 Apr. 1996 & $\mathrm{D}$ & -113.34 & -115.69 & $0.32 \pm 0.09$ \\
\hline
\end{tabular}

Table 1. ERS-1 repeat-pass data takes, their baselines, and on-lake coherence between the interferometric pairs

Notes: All interferometric pairs have 70 day temporal baselines. Correlation coefficients are computed within the lake boundaries over an area of $25 \mathrm{~km}$ by $25 \mathrm{~km}$. The correlation coefficient was not computed for pair 23949/24951 because these data takes do not contain the lake. 
interferometric phase. $\phi_{\text {topography }}$ is simulated using a digital elevation model (DEM) derived from ERS altimetry and the interferometric baselines (provided by J. Bamber). The motion-only phase field, $\phi_{\text {displacement }}$, is then $\phi-\phi_{\text {topography }}$.

To construct the velocity field from ascending and descending data takes, we follow the procedure described in Joughin and others (1998). In general, the velocity vector consists of three components $\left(v_{x}, v_{y}, v_{z}\right)$. For motion tangent to the ice surface, the phase can be written as

$$
\phi_{\text {displacement }}=\frac{4 \pi}{\lambda} \Delta T\left(v_{\mathrm{p}} \sin \theta-v_{z} \cos \theta\right),
$$

where $v_{\mathrm{p}}$ is the motion projected onto a plane tangent to the surface of the ellipsoid. $v_{x}$ and $v_{y}$ are defined on the tangent plane and $v_{z}$ is the vertical motion. The magnitude of $v_{z}$ is approximately

$$
v_{z} \sim v_{\mathrm{p}} \frac{\partial z}{\partial x}
$$

With the surface slope $(\partial z / \partial x)$ around Lake Vostok approximately $0.08^{\circ}\left(\theta=23^{\circ}\right)$ and $v_{\mathrm{p}} \sim 3 \mathrm{~m} \mathrm{a}^{-1}$, the projection of $v_{z}$ onto the range look direction $\left(v_{z} \cos \theta \sim 0.004 \mathrm{~m} \mathrm{a}^{-1}\right)$ contributes $<0.2 \mathrm{rad}$ to the interferometric phase. For our analysis here, we ignore the contribution of this insignificant term. Thus, the ascending and descending data takes each provide an observation to resolve the components of the total velocity vector.

\section{Error analysis}

There are four primary sources of error in the motion estimates:

1. Errors due to uncertainty in the spatial baselines.

2. Errors in the mosaicking.

3. Effect of unaccounted topography (surface relief features which are not resolved in the DEM).

4. Use of a stationary point on ridge $B$ as a velocity tie point.

In the absence of velocity tie points for refining the baseline estimates, we use the precise ERS orbits to determine the interferometric baselines. The radial errors of individual precision orbits are estimated to be approximately $50 \mathrm{~mm}$ (Scharroo and Visser, 1997). The effect of this baseline uncertainty is the introduction of residual linear phase ramps in the range direction due to the incomplete removal of the topographic phase term, $\phi_{\text {topography }}$, which is dependent on the spatial baseline. In our analysis, this residual phase would be interpreted incorrectly as target motion. Simulation shows that a $70 \mathrm{~mm}(\sqrt{2} \times 50 \mathrm{~mm})$ uncertainty in baseline would introduce a maximum phase bias of approximately $\pi / 2 \mathrm{rad}$ ( 0.25 fringe), or an error of approximately $0.1 \mathrm{~m} \mathrm{a}^{-1}$ (or $0.37 / 4 \mathrm{~m} \mathrm{a}^{-1}$ ). This is probably the best-case error.

In practice, we expect a somewhat worse error, as errors propagate when several data takes are mosaicked together relative to a velocity tie point on a reference data take (in this case the reference data take is marked with a cross in Figure lc and d). These errors are especially evident as discontinuities in the motion field constructed using adjacent data takes with very little overlap. On our motion map, the largest seam (approximately $0.25 \mathrm{~m}$, or one contour interval) appears at the seam between the third and fourth data takes from the right. We believe this is by far the largest source of uncertainty in our motion estimates.

There are surface relief variations in the high-resolution
SAR data that are not present in the lower-resolution altimeter DEM. These residuals affect only the small-lengthscale motion because the large-scale DEM is essentially unbiased over relatively smooth terrain. The magnitude of these residuals is dependent on the length of the baseline, especially perpendicular component $B_{\perp}$, because larger baseline interferometers are more sensitive to topographic variations. Since surface slopes are relatively small on the ice sheet, especially over the lake, we do not expect this to be a large source of error in our motion estimates. Figures $1 c$ and d and 2 show the corresponding one-dimensional motion fields derived from ascending and descending passes. Artifacts due to small-scale topography can be seen as rumples in the motion field. These are especially obvious in the motion mosaics when adjacent data takes have very different baselines. For example, the third data take from the right in Figure 1c has a much smaller baseline than its neighbors, thus causing a visible seam in the mosaic.

InSAR measurements provide only relative motion observations. A point on the ridge $\mathrm{B}$ ice divide is selected as the point of no motion (see location in Fig. lc and d) to tie down the motion estimates. Both ascending and descending motion mosaics were referenced to this point. We compare our motion estimate with the only direct measurement of the surface velocity that was made within $20 \mathrm{~km}$ of Vostok station in 1964 and 1972 (Liebert and Leonhardt, 1973), approximately $280 \mathrm{~km}$ away. The astronomical measurements, from star sights, give a velocity of $3.7 \pm 0.7 \mathrm{~m} \mathrm{a}^{-1}$ at $142 \pm 10^{\circ}$ relative to true north. Our estimates give a velocity of $4.2 \mathrm{~m} \mathrm{a}^{-1}$ at $130^{\circ}$ relative to true north, close to the expected uncertainty in our estimates of $0.3 \mathrm{~m} \mathrm{a}^{-1}$ (after accounting for the error sources mentioned above).

\section{RESULTS AND DISGUSSION}

\section{Motion field}

The derived two-dimensional motion field at the overlap between the ascending and descending passes is shown in Figure $2 \mathrm{a}$ and $\mathrm{b}$.

The lake is situated approximately $280 \mathrm{~km}$ east of ridge B. The regional ice dynamics around the lake are controlled by local surface slopes. The velocities west of the lake are small, as the ice flows away from the ice divide. The motion ranges from $0 \mathrm{~m} \mathrm{a}^{-1}$ near the ice divide to around $3 \mathrm{~m} \mathrm{a}^{-1}$ on the western margin of the lake. The derived motion vectors are close to perpendicular to the elevation contours. There is an absence of crevassing along the boundaries of the lake and there is a lack of visible flowlines or lineations in the SAR imagery, probably due to the relatively slow motion and high strength of the very cold ice (Fig. 1).

The influence of the lake on ice motion can be seen in the velocity fields and the velocity contours. Because of the close alignment of the radar look direction relative to the long axis of the lake, the ice motion along the lake is clearest in the one-dimensional flow field derived from the ascending passes (Fig. 1c). A visible southward component of motion can be observed as the ice flows across the western margin. The boundaries of the lake can be easily delineated by the changes in this motion field. Along the $280 \mathrm{~km}$ length of the lake, the surface elevation drops by almost $25 \mathrm{~m}$ on the southern half of the lake (south of $77^{\circ} \mathrm{S}$ ) compared to an elevation change of only $10-15 \mathrm{~m}$ on the northern half (see elevation contours in Fig. 2). The increases in surface 

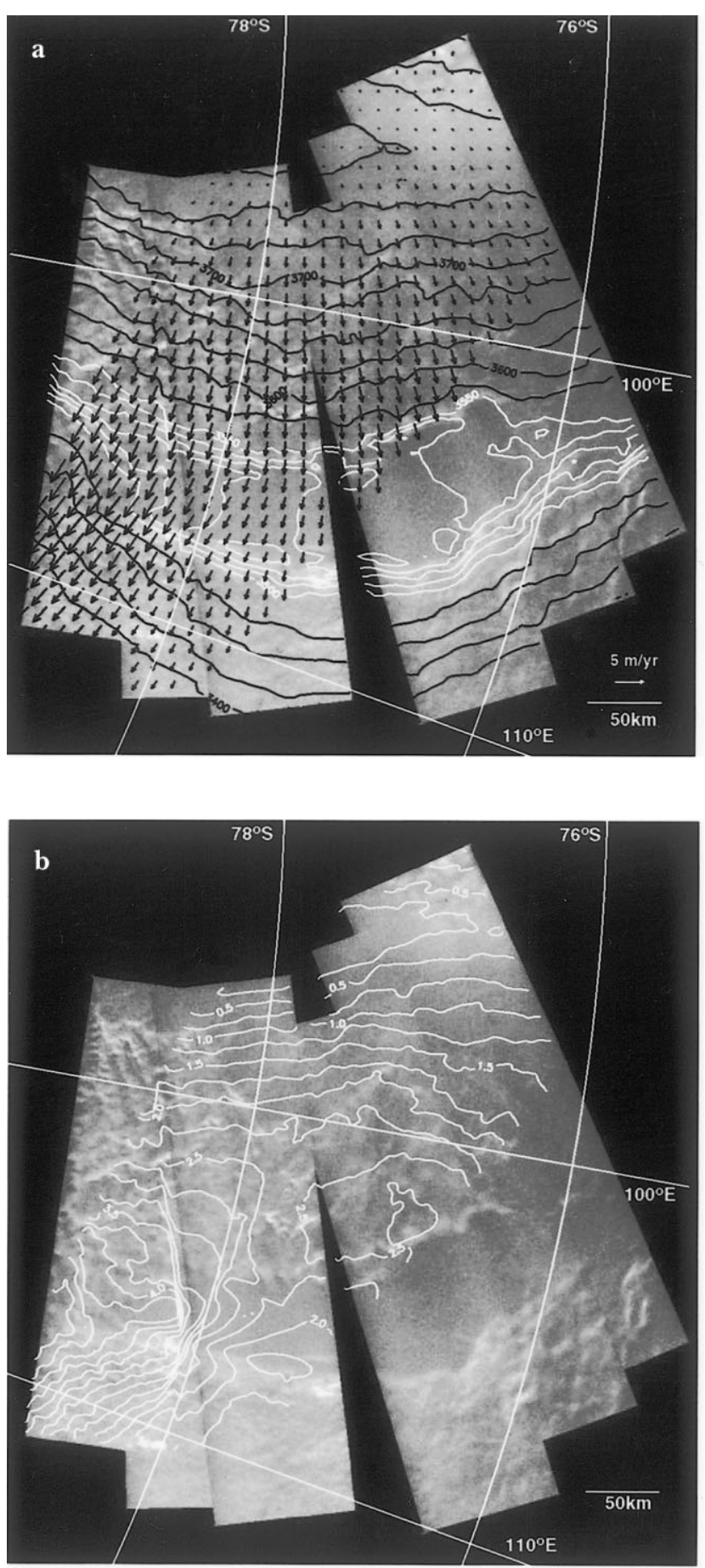

Fig. 2. Two-dimensional vector field computed at the overlap between the ascending and descending data takes. (a) The vector field is overlaid on the image mosaic constructed from ascending and descending passes. Elevation contours are also shown. Contour intervals of the black-and-white contours are 25 and $10 \mathrm{~m}$, respectively. (b) Velocity contours of the derived two-dimensional vector field (contour interval $0.25 \mathrm{~m} \mathrm{a}^{-1}$ ). The contoured velocity field shows a seam of approximately $0.25 \mathrm{ma}^{-1}$ in the mosaic.

velocity are well correlated to increases in the surface slope of the lake; the ice motion is slower on the northern than on the southern half of the lake. The velocity varies between 2 and $4.5 \mathrm{~m} \mathrm{a}^{-1}$ in the southern half, and the velocity gradients (Fig. 2) are highest near Vostok station. The increase in the southward component is highly correlated to the surface slope of the lake. Away from the lake-boundaries effects, the across-lake flow pattern (in the southern half) takes on a close to parabolic profile, with maximum velocity close to the center line of the lake. Absence of basal drag allows ice flow to respond quickly to small changes in surface slopes.

In the east-west direction, the ice surface is relatively flat, with less than several meters of drop in elevation between the lake margins. The across-lake motion prevails - the ice does not flow perpendicular to the surface slopes. The flow slows as the ice sheet re-grounds on the eastern margin. East of the lake, the derived flow pattern is again close to perpendicular to the elevation contours. Overall, the presence of the lake adds a southward component to the west-east flow of the ice sheet.

\section{Mass balance}

Due to the influence of the lake, a certain volume of the ice is diverted southward, although not as much as if all the ice had to flow through the southern lakeshore. Mean flow velocities of $2-3 \mathrm{~m} \mathrm{a}^{-1}$ across the $280 \mathrm{~km}$ wide, $3.5 \mathrm{~km}$ thick western margin result in a flux of $3.0 \times 10^{9} \mathrm{~m}^{3} \mathrm{a}^{-1}$. If we assume that the southern boundary is $25 \mathrm{~km}$ wide, using the motion profile the southward mass flux would be approximately $3.0 \times 10^{8} \mathrm{~m}^{3} \mathrm{a}^{-1}$. The southward component due to the influence of the lake diverts approximately $10 \%$ of the mass in this direction.

\section{Origins of the Vostok ice core}

Assuming a steady-state motion field, we can construct motion trajectories to determine the approximate origins of ice particles on the lake. Figure 3 shows several trajectories, including one with a termination point at Vostok station, created by back propagation of the flow field. The trajectory shows that the ice at the present-day location of Vostok station was grounded on the west side of Lake Vostok $<5000$ years ago. This has certain implications concerning the thermal and mechanical processes of the accretion ice near the bottom of the lake ice.

Recent analysis of heat flow and internal deformational heating (Salamatin and others, 1998) suggests subglacial (lake-ice) growth rates of $1-4 \mathrm{~mm} \mathrm{a}^{-1}$, depending on the level of strain heating from shear between moving and stationary ice. The entire layer of accretion ice is $210 \mathrm{~m}$ thick, but this ice is actually two strata, one containing visible mineralogic inclusions (70 $\mathrm{m}$ thick) above a cleaner layer $(140 \mathrm{~m}$ thick) characterized by very large crystals (Jouzel and others, 1999; Lipenkov and Barkov, 1998; Petit, 1999). If all the accretion ice is from Lake Vostok, the time implied for passage over water is $53-220$ kyr. If only the clean-ice stratum is from the lake, the time over water is $35-140 \mathrm{kyr}$. In either case, the joint growth rate and thickness lead to an inference that the ice on which Vostok station rests had been in accretion for about 10 times longer than the velocity data indicate is possible. This discrepancy is too large to be accommodated in the growth-rate uncertainty, which is well established, and it is unlikely that the ice motion changed dramatically over the past 5000 years. The ice motion suggests a freezing rate of approximately $40 \mathrm{~mm} \mathrm{a}^{-1}$. Freezing rates of the order of centimeters per year are also suggested in a recent analysis by Siegert and others (2000). They inferred the freezing rate by measuring the increase in ice thickness between the basal internal layers and the base of the ice sheet along the direction of flow. The discrepancies in the inferred freezing rates estimated here and by Siegert and others (2000) and the model freezing rates (Salamatin and others, 1998) should be examined. 


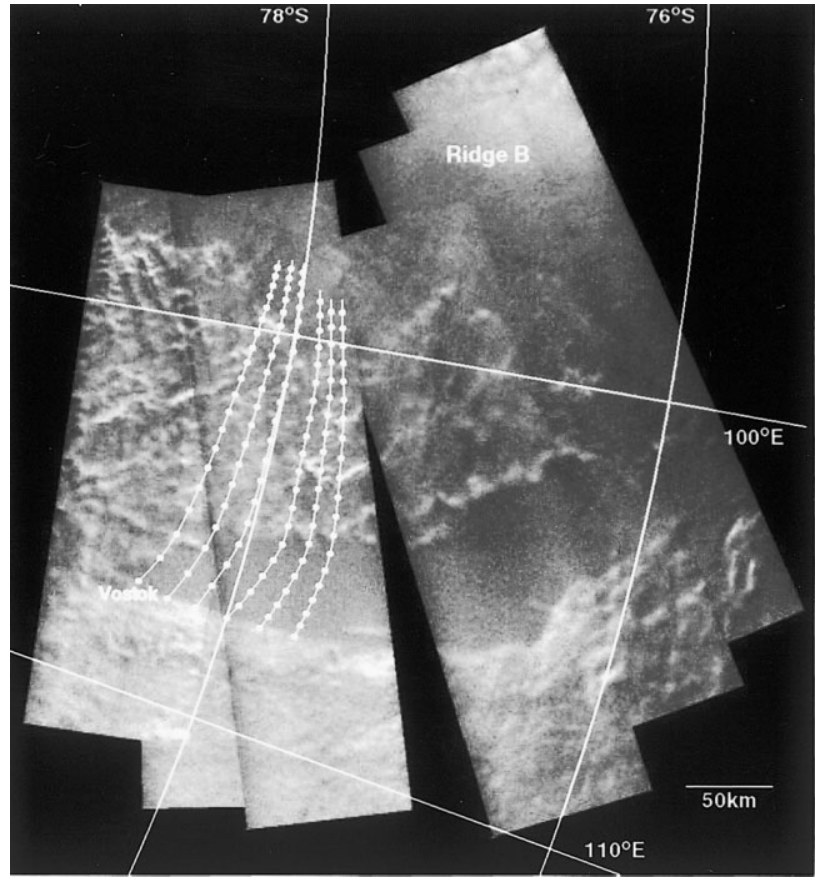

Fig. 3. 100000 year trajectories showing the origins of ice parcels on different parts of the ice sheet. The time interval between filled circles along the path is 5000 years.

\section{SUMMARY}

The motion field over Lake Vostok is measured using repeatpass SAR interferometry with a relatively long temporal baseline of 70 days. The two-dimensional vector field is resolved using observations from ascending and descending look directions. The regional flow of glacial ice surrounding Lake Vostok is controlled by the west-east surface slopes of the ice sheet. Over the lake, measurements show that there is an observable southward component of motion which can be explained by surface slopes along the length of the lake and by the absence of basal drag. The prevailing east-west flow of the ice-sheet motion is modified by this southward motion. Specifically, the ice-sheet velocity over the lake is greatest near Vostok station $\left(4.2 \mathrm{~m} \mathrm{a}^{-1}\right)$ and is slowest toward the northern end of the lake, where ice velocity is $<1 \mathrm{~m} \mathrm{a}^{-1}$. Between the lake boundaries, the southward velocity profile exhibits a parabolic profile. The ice-velocity field allows us to reconstruct ice flowlines across the lake, and constrain the residence time of the ice over the lake. The line crossing the Vostok ice-core site shows that the ice within the core could have been grounded upstream of Lake Vostok about 5000 years ago. Since $210 \mathrm{~m}$ of ice have been accreted to the underside of the ice sheet from the lake, we attribute a minimum freezing rate of around $40 \mathrm{~mm} \mathrm{a}^{-1}, 10$ times greater than that inferred from thermodynamic modeling of the upper $2 \mathrm{~km}$ of the ice core.

\section{ACKNOWLEDGEMENTS}

We wish to thankJ. L. Bamber, University of Bristol, for providing the DEM of Antarctica for our study. The ERS-1/-2 radar data were provided by the ASF, University of Alaska, Fairbanks, AK. The authors wish to thank S. Pang for providing software support. R. Kwok and F. D. Carsey performed this work at the Jet Propulsion Laboratory, California Institute of Technology, under contract with the U.S. National Aeronautics and Space Administration.

\section{REFERENGES}

Goldstein, R. M., H. Engelhardt, B. Kamb and R. M. Frolich. 1993. Satellite radar interferometry for monitoring ice sheet motion: application to an Antarctic ice stream. Science, 262(5139), 1525-1530.

Hoen, E. W. and H. A. Zebker. 1999. Penetration depth inferred from interferometric volume decorrelation observed over the Greenland ice sheet. In IGARSS '99. 19th International Geoscience and Remote Sensing Symposium, 28 fune-2 July 1999, Hamburg, Germany. Proceedings. Piscataway, NJ, Institute of Electrical and Electronics Engineers, CD-ROM.

Joughin, I. R., R. Kwok and M. A. Fahnestock. 1998. Interferometric estimation of three-dimensional ice-flow using ascending and descending passes. IEEE Trans. Geosci. Remote Sensing, GE-36(1), 25-37.

Jouzel, J. and 9 others. 1999. More than $200 \mathrm{~m}$ of lake ice above subglacial Lake Vostok, Antarctica. Science, 286(5447), 2138-2141.

Kapitsa, A. P., J. K. Ridley, G. de Q. Robin, M. J. Siegert and I. Zotikov. 1996. A large deep freshwater lake beneath the ice of central East Antarctica. Nature, 381(6584), 684-686.

Kwok, R. and M. A. Fahnestock. 1996. Ice sheet motion and topography from radar interferometry. IEEE Trans. Geosci. Remote Sensing, GE-34(1), 189-200.

Liebert, J. and G. Leonhardt. 1973. Astronomic observations for determining ice movement in the Vostok station area. Sov. Antarct. Exped. Inf. Bull., 8 (10), 569-570

Lipenkov, V. Ya. and N. I. Barkov. 1998. Internal structure of the Antarctic ice sheet as revealed by deep core drilling at Vostok station. In LakeVostok study: scientific objectives and technological requirements. International workshop. Abstracts. St. Petersburg, Arctic and Antarctic Institute, 31-35.

Petit, J.-R. 1999. Evidence from the Lake Vostok ice core studies. In Bell, R. E. and D. M. Karl, eds. Lake Vostok final workshop report. New York, Columbia University Press, 16-17.

Ridley, J. K., W. Cudlip and S.W. Laxon. 1993. Identification of subglacial lakes using ERS-1 radar altimeter. f. Glaciol., 39(133), 625-634.

Robin, G. de Q., D. J. Drewry and D. T. Meldrum. 1977. International studies of ice sheet and bedrock. Philos. Trans. R. Soc. London, Ser. B, 279(963), 185-196.

Salamatin, A. N., R. N. Vostretsov, R. Petit, V.Ya. Lipenkov and N. I. Barkov. 1998. Geophysical and palaeoclimatic implications of the stacked temperature profile from the deep borehole at Vostok station, Antarctica. Mater. Glyatsiol. Issled. 85, 233-240.

Scharroo, R. and P. N. A. M. Visser. 1997. ERS tandem mission orbits; is $5 \mathrm{~cm}$ still a challenge? In Third ERS Scientific Symposium, 17-21 March 1997, Florence, Italy. Proceedings. Frascati, Italy, European Space Agency, 200-205. (ESA Publication SP-414.)

Siegert, M. J. and J. K. Ridley. 1998. An analysis of the ice-sheet surface and subsurface topography above the Vostok Station subglacial lake, central East Antarctica. 7. Geophys. Res., 103(B5), 10,195-10,208.

Siegert, M. J., R. Kwok, C. Mayer and B. Hubbard. 2000. Water exchange between the subglacial Lake Vostok and the overlying ice sheet. Nature, 403(6770), 643-646. 